\title{
Measuring and Modelling Transpiration Versus Evapotranspiration of a Tomato Crop Grown on Soil in a Mediterranean Greenhouse
}

F.J. Baptista

Universidade de Évora, Departamento de

Engenharia Rural, Núcleo da Mitra

Apartado 94. 7002-554 Évora

Portugal
B.J. Bailey

Silsoe Research Institute, Process

Engineering Division, Wrest Park, Silsoe

Bedford MK45 4HS

United Kingdom

J.F. Meneses

Instituto Superior de Agronomia,

Departamento de Engenharia Rural, Tapada

da Ajuda. 1399-017 Lisboa

Portugal

Keywords: modelling, evapotranspiration, transpiration, tomato crop

Abstract

The main sources of water vapour in a greenhouse are plant transpiration and the evaporation of water from soil (evapotranspiration). These processes are influenced by environmental factors such as solar radiation and water vapour pressure deficit, as shown by the Penman-Monteith equation. Most previous studies have been conducted in Northern countries and with soiless crops, which means that they only refer to transpiration. In Mediterranean greenhouses many crops are still grown on soil, so evaporation adds another component to the water vapour balance.

The purpose of this study was: 1 - to measure the evapotranspiration (soil and crop) and transpiration (crop), of a tomato crop grown on a heavy soil using a lysimeter; 2 - to develop models as a function of the inside solar radiation and water vapour pressure deficit; 3 - to validate the models using data from different days and 4 - to compare the models.

Experiments were conducted in a Mediterranean unheated greenhouse covered with co-extruded PE-EVA-PE film, with a soil grown tomato crop, located in Lisbon. The orientation was east-west and ventilation was achieved by continuous apertures located on the side walls over its entire length. Trickle ferti-irrigation tubes were located between each two rows of plants. Climatic parameters, such as dry and wet bulb air temperatures, crop and leaf temperatures and solar radiation were measured and recorded using a data logger. Information on the evolution of the crop was also recorded.

To compute evapotranspiration and transpiration a lysimeter was used and data of irrigation, drainage and soil moisture content were recorded. For the evaluation of the transpiration, the lysimeter was covered with a plastic film to prevent evaporation from the soil.

To develop the models, data were recorded over periods of several days at different stages of plant development and another set of data from different periods was used for model validation. Comparison between measured and estimated data shows good agreement for both models. Differences between transpiration and evapotranspiration were very small, which reveals that, under the conditions experienced, evaporation from the soil can be neglected when trickle ferti-irrigation is used.

\section{INTRODUCTION}

Evapotranspiration of greenhouse crops is a very important tool for greenhouse climate control and irrigation management (Stanghellini, 1987; Yang et al., 1990; Jolliet and Bailey, 1992; Baille et al., 1994; Baptista et al., 2000; Rana and Katerji, 2000; Seginer, 2002). Consequently, it has been studied by several authors and several models 